\title{
Lifetime commercial heterosexual behavior among HIV negative elderly men from rural Chengdu, China: a modified knowledge- attitude-practice perspective
}

Yi Yang ${ }^{1 *}$, Hua Deng ${ }^{2}$, Huan $\mathrm{He}^{3}$, Shuang Feng Fan ${ }^{4}$, Yuan $\mathrm{Li}^{5}$, Xia $\mathrm{Wu}^{6}, \mathrm{Na} \mathrm{Li}^{6}$, Jing Xi ${ }^{4}$, Jing Xu ${ }^{1}$, Jie Xiao , Rui Ping Liao ${ }^{6}$ and Wei Xiao ${ }^{6}$

\begin{abstract}
Background: China is facing big challenges to achieve the "90-90-90 targets". The HIV prevalence of elderly ( $\geq 50$ years) men have been steadily increasing in China, mainly through the sexual transmission route, but sexual behaviors of them are far from well-studied. In 2019, elderly men accounted for 59.2\% of HIV/AIDS cases in Sichuan, China.

Methods: The research design is a cross-sectional study. Face-to-face interviews were conducted among 795 HIV negative elderly men from rural Chengdu, capital City of Sichuan. Bivariate and multivariate logistic regression models were applied to examine factors associated with commercial heterosexual behavior from a modified KnowledgeAttitude-Practice (KAP) perspective.

Results: 129 (16.23\%) respondents admitted high-risk sexual behaviors, including 11.07\% commercial heterosexual behavior, $6.16 \%$ extramarital, $2.89 \%$ casual and $0.25 \%$ homosexual behavior, and no one used condom consistently. 427(68.43\%) had ever gotten HIV-related Health Education (HRHE), mainly through mass media (70.49\%). The HIVrelated knowledge awareness rate was only $31.41 \%$. Migration history ( $A O R=2.46,95 \% \mathrm{Cl}=1.02-5.91)$, age ( $\geq 60$ vs. $50-$ $59, \mathrm{OR}=0.41,95 \% \mathrm{Cl}=0.19-0.91)$, receiving HRHE from mass media $(\mathrm{OR}=0.37,95 \% \mathrm{Cl}=0.16-0.85)$, marital status (married vs. never married, $\mathrm{OR}=0.04,95 \% \mathrm{Cl}=0-0.52$ ), and undecided ( $\mathrm{AOR}=0.02,95 \% \mathrm{Cl}=0.01-0.09$ ) and objection $(A O R=0.04,95 \% \mathrm{Cl}=0.01-0.1)$ attitude toward commercial sex were related to lifetime commercial heterosexual behavior.

Conclusions: High-risk sexual behaviors are common among elderly men from rural areas in Chengdu. Receiving HRHE from mass media and undecided and objection attitude toward commercial sex prevent elderly from being involving in commercial heterosexual behavior. According to the results, health facilities should continue to conduct systematic interventions, paying more attention to 50-59years old group. Sex and condom use need to be talked in public. Working with mass media, health facilities give elderly men education not only focusing on HIV/AIDS, but also on knowledge and skills of condom use.
\end{abstract}

Keywords: Sexual behavior, Elderly men, Knowledge-attitude-practice (KAP) model, HIV, China

\footnotetext{
* Correspondence: thehanyang@163.com

'Department of Social Medicine and Health Administration, School of

Administration, Chengdu University of Traditional Chinese Medicine, 1166

Liutai Avenue, Wenjiang District, Chengdu 611137, China

Full list of author information is available at the end of the article
}

(c) The Author(s). 2021 Open Access This article is licensed under a Creative Commons Attribution 4.0 International License, which permits use, sharing, adaptation, distribution and reproduction in any medium or format, as long as you give appropriate credit to the original author(s) and the source, provide a link to the Creative Commons licence, and indicate if changes were made. The images or other third party material in this article are included in the article's Creative Commons licence, unless indicated otherwise in a credit line to the material. If material is not included in the article's Creative Commons licence and your intended use is not permitted by statutory regulation or exceeds the permitted use, you will need to obtain permission directly from the copyright holder. To view a copy of this licence, visit http://creativecommons.org/licenses/by/4.0/ The Creative Commons Public Domain Dedication waiver (http://creativecommons.org/publicdomain/zero/1.0/) applies to the data made available in this article, unless otherwise stated in a credit line to the data. 


\section{Introduction}

Benefiting from a scale-up of antiretroviral therapy (ART) and prevention of mother-to-child transmission in the past two decades, annual incidences and mortality rates of human immunodeficiency virus/Acquired Immune Deficiency Syndrome (HIV/AIDS) have been declining $[1,2]$. The declining leads to ambitious calls to end the HIV/AIDS epidemic as a public health threat by 2030 [3]. The Joint United Nations Programme on HIV/ AIDS (UNAIDS) proposed the "90-90-90 targets", which aims to have $90 \%$ of people living with HIV (PLHIV) knowing their status, $90 \%$ of those diagnosed receiving sustained ART, and 90\% of those receiving ART achieving viral suppression by 2020 [4].

China is facing big challenges to achieve the "90-9090 targets" $[5,6]$. One of the biggest challenges is that the HIV prevalence of elderly ( $\geq 50$ years old) men has been steadily increasing, mainly through the sexual transmission route [7-12]. Due to immune functional decline and increased vulnerability to infections [13], HIV infected elderly men quickly progress into AIDS even deaths $[9,13]$. Being considered as sexually inactive [14], elderly men had been excluded from the priority of HIV/AIDS prevention programs [15-18], and are not recognized and listed as a key HIV prevention group until 2017 for the first time in China [19]. On one hand, current elderly men are from 20 to 50-year-old group, who are previously sexually active and might be HIV infected as clients of female commercial sex workers (FCSW) [20-25] and men who have sex with men (MSM) [26-30], especially when they migrate [31-33] but not detected. On the other hand, they could be a newly infected group. Compared with other age groups, elderly men have minimal knowledge about HIV [34], condom use among them is even lower [25, 35, 36].

Located in the southwest of China, Sichuan is one of the few provinces heavily affected by the HIV/AIDS epidemic where heterosexual transmission increased from $65.3 \%$ of total cases in 2008 to $98.2 \%$ in 2019 [37]. People over 50 years old in Sichuan accounted for less than $5 \%$ of HIV/AIDS cases in 2005, but over $40 \%$ in 2017 , and $59.2 \%$ in 2019, meanwhile the proportion of elderly men in the population is less than $40 \%[5,37,38]$ .One of fifth PLHIV in Sichuan are from Chengdu [5, 37], the capital city. Based on case report system at population level $[9,10,37]$, heterosexual transmission has been widely accepted as the major route for HIV epidemics in China. Why are elderly men involved in high risky sexual behaviors? Since the 1980s, rural-to-urban migration have been part of their lives for men from rural areas in China, and increased the possibility of being involved in high risky sexual behaviors [31-33]. According to knowledge-attitude-practice (KAP) model $[25,34-36,39,40]$ which has been applied in HIV prevention since 1990s, the hypothesis flows are the following: elderly men are involved in high risky sexual behaviors because they don't believe these behaviors are highly risky. Why don't they believe? Because they don't have enough knowledge. In order to help them to avoid high risky sexual behaviors, it is necessary to give them health education to improve knowledge level. Though KAP model has been proved not as effectively as expected [25], due to their minimal knowledge about HIV [34], current comprehensive HIV prevention strategies in Sichuan is based on KAP [5] .

Sexual behaviors of elderly men in China are far from well-studied. In 2019, 1 year before 2020 when the "9090-90 targets" are expected to be achieved, our team conducted a cross-sectional investigation to understand sexual behaviors among elderly men in Chengdu, China where HIV prevalence of them have been increasing in recent years and HIV prevalence of MSM has been consistently high [5].

\section{Methods \\ Study site}

With the coverage of sentinel surveillance improving [5] and huge number of residents, rural County $\mathrm{A}$ in Chengdu ranked one of the top five counties in the number of PLHIV, mainly from male group.

\section{Study process}

The research design is a cross-sectional study. According to the surveillance information from the web-based $\mathrm{Na}$ tional HIV/AIDS Comprehensive Response Information Management System (CRIMS), public health workers from County A center for disease prevention and control (CDC) selected the top six towns in HIV infection number to be the study sites. We conducted two pilot investigations to test the questionnaire and to adjust the investigation procedure and manual before the formal investigation.

Male interviewers were trained through three steps: before pilot investigation, pilot investigation and at site. Six male interviewers, who were well trained and pasted the interviewers' test, conducted the investigation.

\section{Participants and investigation}

Multistage cluster random sampling and multistage probability proportional stratified systematic sampling were applied to recruit eligible respondents. The hierarchy in County A is county-town-village-village group. In four of six towns, multistage cluster random sampling was applied. Firstly, one village from each town was randomly selected, then one village group was randomly selected. All eligible elderly men in the village group were invited to participate the study. In the other two of six towns, multistage probability proportional stratified 
systematic sampling were applied. According to the total number of elderly men in each village group and their proportion in each town, the sampling size for each village group were confirmed.

Resident roster was used to sample the potential respondents.

The selection criteria included: (1) $\geq 50$ years old; (2) male; (3) live in the current address for at least 6 months. After eligibility was determined and a written informed consent was completed, a 30-min face-to-face structured interview was conducted in a private room by one well-trained male interviewer to make sure the respondents felt comfortable to talk about their sexual behaviors. Local slangs were used to refer sexual behaviors. Completed questionnaires were inspected at the sites to ensure no missing items, wrong information or logical errors. All participants got a big bottle of dishwashing liquid (approximately valued 2 USD) for their participation (no matter completing the questionnaire or not). From June to July 2019, 802 men were recruited, and 797(99.38\%) questionnaires were reliable.

\section{HIV rapid testing}

According to the sentinel surveillance routine procedure in the township health centers, HIV rapid testing was conducted through two ways. The first method was sampling a 3-5 ml cubital venous blood of each respondent at the investigation sites and sending it to a local laboratory. An enzyme-linked immunosorbent assay (ELISA) was used for HIV antibody test. The other method was using Dot immunocolloid gold rapid test (Yingke New Technology Co., Ltd.) at the investigation sites where immediate results will be showed. In total, 2 of 797 were fast tested HIV positive.

\section{Measures}

Based on the current HIV/AIDS programs strategies in Sichuan [5] and literature [25, 35, 36, 39, 40], a modified KAP model was applied. Attitudes were reflected by sexual attitude, self-identified vulnerability, and HIV-related sigma. High-risk sexual behaviors included commercial heterosexual behavior, extramarital sexual behavior, casual sexual behavior, and homosexual behavior. Demographic characteristics, migration experiences [31-33], HIV-related health education (HRHE), sexual identity, and sexual desire change were taken as controlling factors for KAP model.

\section{HIV-related knowledge}

According to United Nations General Assembly Special Session on HIV/AIDS (UNGASS) indicator [40], eight survey questions (China National Eight) (Cronbach's Alpha $=0.77)$ were used to assess HIV-related knowledge (detail in Table 3). Respondents received one point for each correctly answered question. The sum of the eight questions represented respondents' HIV related knowledge level. Respondents were categorized into two groups: 'know' (score greater than 5) and 'do not know' (score equal and less than 5).

\section{Sexual attitude}

"How do you think about visiting FCSW?" was asked to measure their attitude toward commercial heterosexual behavior. The response options were: (1) it is understandable as a common human behavior; (2) undecided; (3) could not accept; (4) strongly objection. Besides the above four response options, "admiring" was considered as one option toward "How do you think about extramarital sexual behavior". The response options toward "How do you think about homosexual behavior" were: (1) it is understandable and he has homosexual behavior; (2) it is understandable but not acceptable; (3) could not accept; (4) could not accept but be involved in; (5) strongly objection; (6) do not know what homosexual behavior is.

\section{Data analysis}

Seven hundred ninety-five of 797 (99.75\%) respondents who were HIV negative were included in the current analyses. Frequencies of nominal variables, mean and standard deviation for interval variables were assessed. Commercial heterosexual behavior was the most common high-risk sexual behavior. T test, ANOVA and chisquare tests were used to examine the relationships between commercial heterosexual behavior and independent variables including HIV-related knowledge, attitude and controlling factors. Binary logistic regression with backward stepwise selection was applied to examine factors associated with commercial heterosexual behavior, including all factors with $p<0.10$ in bivariate analyses. 624(78.49\%) who heard about HIV/AIDS were included in the logistic analysis. Adjusted odds ratio (AOR) and 95\% confidence intervals were calculated. Factors with AOR greater than one was categorized as risk factors, and less than one was categorized as protective factors.

\section{Results}

\section{Basic information}

Demographic characteristics and migration experiences are showed in Table 1. Four of $795(0.50 \%)$ respondents admitted that they had used illicit drugs but not through injection. They only used Opium, reported none highrisk sexual behavior, and were tested as HIV negative.

\section{Sexual identity and sexual desire change}

Seven hundred ninety-two of 795(99.62\%) reported that they are heterosexual, $2(0.25 \%)$ as bisexual, and 1 respondent $(0.13 \%)$ reported that he had never heard of 
Table 1 Demographic characteristics and Migration Experiences of among HIV negative elderly men in Chengdu, China $(n=795)$

\begin{tabular}{|c|c|c|c|}
\hline & $n(\%)$ & & $\mathrm{n}(\%)$ \\
\hline Age & & Daily entertainment & \\
\hline $50-59$ & $221(27.8)$ & Visiting teahouse with friends & $512(64.40)$ \\
\hline $60-69$ & $375(47.17)$ & Playing mahjong & $359(45.16)$ \\
\hline $70-79$ & $171(21.51)$ & Tourism & $36(4.53)$ \\
\hline $80-87$ & $28(3.52)$ & Having party with friends & $132(16.6)$ \\
\hline Household residency & & Exercises & $159(20.00)$ \\
\hline rural & $784(98.6)$ & Dancing at squares & $3(0.38)$ \\
\hline urban & $11(1.4)$ & Watching TV & $452(56.86)$ \\
\hline Latest occupation & & Other & $146(18.36)$ \\
\hline Farm workers & $371(46.7)$ & Monthly income & \\
\hline Laborers & $273(34.3)$ & No personal income & $64(8.05)$ \\
\hline Government employees & $28(3.5)$ & $<1000 Y U A N$ & $368(46.29)$ \\
\hline Other & $123(15.5)$ & 1000-1999YUAN & $191(24.03)$ \\
\hline Education level & & 2000-2999YUAN & $78(9.81)$ \\
\hline Primary school drop outs & $350(44.03)$ & 3000-3999YUAN & $52(6.54)$ \\
\hline Primary school & $179(22.52)$ & 4000YUAN and above & $42(5.28)$ \\
\hline Junior high school & $207(26.04)$ & Monthly expense for entertainment & \\
\hline Senior high school and above & $59(7.42)$ & $<500 Y U A N$ & $629(79.12)$ \\
\hline Marital status & & 500-999YUAN & $103(12.96)$ \\
\hline Never married & $17(2.14)$ & 1000-1499YUAN & $37(4.65)$ \\
\hline Married & $648(81.51)$ & 1500-1999YUAN & $14(1.76)$ \\
\hline Separated & $44(5.53)$ & 2000YUAN and above & $12(1.51)$ \\
\hline divorce/widow with fixed sexual partner & $16(2.01)$ & Migration & \\
\hline Single (divorce/widow) & $70(8.81)$ & More than one year ago & $382(48.05)$ \\
\hline Living with & & Within the past one year & $120(15.09)$ \\
\hline Only spouse & $306(38.49)$ & Never & $293(36.86)$ \\
\hline Spouses and other family members (parents or children) & $364(45.79)$ & Migration site & \\
\hline Only other family members (parents or children) & $41(5.16)$ & Other towns in County A & $317(63.15)$ \\
\hline Nobody & $78(9.81)$ & Other subdistricts in the city of Chengdu & $165(32.87)$ \\
\hline \multirow[t]{2}{*}{ In facilities } & $6(0.75)$ & Other cities in Sichuan Province & $200(39.84)$ \\
\hline & & Other provinces & $130(25.95)$ \\
\hline
\end{tabular}

homosexuality. Five hundred forty-two of 795(68.2\%) respondents reported that their sexual desire has declined, $19.2 \%$ reported no change, $11.9 \%$ had no sexual need, and $0.6 \%$ reported increasing desire after the age of 50.

\section{HIV-related health education}

Four hundred twenty-seven of 624(68.43\%) respondents reported having ever gotten HRHE, mainly through mass media (TV, internet, and radio) $(70.49 \%)$ and health facilities (CDC, hospitals, and township health centers) (58.31\%). Before this investigation, 234 of $427(54.80 \%)$ received HRHE from village doctors and health workers from township health center. The details are showed in Table 2.

\section{HIV-related knowledge level}

The HIV-related knowledge awareness rate was $31.41 \%$, and only 20 people $(3.21 \%)$ scored eight of "China National Eight." The details are showed in Table 3.

\section{Sexual attitudes}

The majority (41.38\%) of 795 respondents reported that they could not accept commercial heterosexual behavior, $29.69 \%$ held undecided standpoint, $18.36 \%$ said it is understandable as natural human behavior, and only $10.57 \%$ reported strong objection. The percentages of corresponding attitudes toward extramarital sexual behaviors were 42.64, 29.56\%,12.45 and $14.21 \%$. Moreover, 9 of $795(1.13 \%)$ reported that they admired the ones 
Table 2 Channels of HIV-related Health Education (HRHE) among HIV negative elderly men who had ever gotten HRHE $(n=427)$

\begin{tabular}{|c|c|c|c|}
\hline Channel & n (\%) & Latest Providers & n (\%) \\
\hline TV, internet, and radio & $301(70.49)$ & $\begin{array}{l}\text { health workers from township health center and village } \\
\text { doctors }\end{array}$ & $\begin{array}{l}234 \\
(54.80)\end{array}$ \\
\hline $\begin{array}{l}\text { health facilities (CDC, hospitals, and township health } \\
\text { centers) }\end{array}$ & $249(58.31)$ & public health workers from CDC & $\begin{array}{l}111 \\
(26.00)\end{array}$ \\
\hline families, relatives, friends and neighbors & $95(22.25)$ & civil servant from township governments & $67(15.69)$ \\
\hline magazines, newspaper, and books & $47(11.01)$ & village cadre & $49(11.48)$ \\
\hline \multirow[t]{5}{*}{ others } & $7(1.64)$ & others & $34(7.96)$ \\
\hline & & doctors from other hospitals & $23(5.39)$ \\
\hline & & grandchild's teachers & $2(0.47)$ \\
\hline & & volunteers & $1(0.23)$ \\
\hline & & pharmacist & 0 \\
\hline
\end{tabular}

who had extramarital sexual behaviors. In terms of the attitude toward homosexual behavior, $42.26 \%$ reported that they do not know what homosexual behavior is, $32.96 \%$ strong objection, $17.23 \%$ objection, and $7.30 \%$ reported it understandable but not acceptable, and $0.25 \%$ reported it is understandable and they had homosexual behavior.

\section{HIV vulnerability and HIV-related stigma}

Forty-eight of 624 (7.69\%) reported that they were at risk of HIV infection. If their relatives/friends got HIV infected, $29.65 \%$ reported that they would be fearful and choose to stay far away, $23.88 \%$ would express sympathy but still choose to stay away, $22.60 \%$ would show sympathy and want to keep in touch, $12.66 \%$ stated they would treat him/her as usual, and only $11.22 \%$ would like to care for him/her more.

\section{Sexual behaviors}

Seven hundred eighty-four of 795(98.62\%) reported that they had sexual partners in their lifetime. 129 (16.23\%) respondents admitted high-risk sexual behaviors, among which the prevalence of commercial heterosexual behavior was $11.07 \%$, extramarital sexual behavior $6.16 \%$, casual sexual behavior $2.89 \%$, and homosexual behavior $0.25 \%$. $20(2.52 \%)$ and $2(0.25 \%)$ were involved in two and three types of above high-risk sexual behaviors.

One of the self-identified bisexual respondents reported that he was involved in of the above sex activities throughout his lifetime. Another self-identified bisexual respondent was involved in commercial heterosexual behavior and homosexual behavior.

\section{Commercial heterosexual behavior}

Eighty-eight of $795(11.07 \%)$ respondents admitted they have patronized FCSWs in their lifetime. Their first patronization happened at the age of $33.90 \pm 13.43$, mainly in other towns in County A (42.53\%) where they worked outside of their hometown (83.82\%).
These patronizations mostly followed their friends (43.02\%) and suggestions from other strangers (40.70\%), mainly due to "divorce or separate, purely to solve with physical need" (60.92\%), "lonely" (52.87\%), and "invited by peers" (43.68\%). Generally, they preferred to patronize a different FCSW (62.07\%), and $13.79 \%$ patronized the same FCSW every time.

Only 16 of $88(20.00 \%)$ reported that they patronized FCSW in the past 1 year, mainly at illegal street side brothels (50.00\%) and tea houses (37.50\%), at the price of $¥ 20-49$ (3-7USD) (68.75\%). None of them used condoms consistently, $68.75 \%$ had never used a condom. The main reasons for lack of condom use was "never use condom, don't know how to use" (43.75\%) and "FCSW looks healthy" (31.25\%).

\section{Commercial heterosexual behavior related factors}

In bivariate analysis, commercial heterosexual behavior was not related to HIV-related knowledge level, attitude

Table 3 HIV-related Knowledge awareness among HIV negative elderly men who had heard about HIV/AIDS $(n=624)$

\begin{tabular}{ll}
\hline item & n (\%) \\
\hline $\begin{array}{l}\text { Is it possible to get HIV by sharing a syringe } \\
\text { with someone living with HIV/AIDS? }\end{array}$ & $417(66.83)$ \\
$\begin{array}{l}\text { Will a person get HIV by transfusion of blood } \\
\text { with HIV? }\end{array}$ & 409 (65.54) \\
$\begin{array}{l}\text { Is it possible for a child born to a woman infected } \\
\text { with HIV to get HIV? }\end{array}$ & $342(54.81)$ \\
Can a healthy-looking person have HIV? & $330(52.88)$ \\
Can having sex with only one faithful, uninfected & $314(50.32)$ \\
partner reduce the risk of HIV transmission? & \\
Can using condoms reduce the risk of HIV transmission? & 264 (42.31) \\
$\begin{array}{l}\text { Can a person get HIV by sharing a meal with } \\
\text { someone who is infected? }\end{array}$ & 238 (38.14) \\
A person can get HIV from mosquito bites. & $133(21.31)$ \\
HIV-related Knowledge awareness rate & $196(31.41)$ \\
All correct & $20(3.21)$ \\
\hline
\end{tabular}


toward extramarital sexual behavior, casual sexual behavior, and homosexual behavior, sexual identity, and sexual desire change $(P>0.05)$. The prevalence of commercial heterosexual behavior among the ones who had ever migrated was $13.55 \%$, higher than among the ones who had never migrated $(7.12 \%)\left(x^{2}=7.734, P<0.01\right)$.

Factors associated with commercial heterosexual behavior in bivariate and multivariate analyses are showed in Table 4 . The greatest magnitude of a protective factor was undecided (AOR $=0.02,95 \% \mathrm{CI}=0.01-0.09$ ) and objection (AOR $=0.04,95 \% \mathrm{CI}=0.01-0.1)$ attitude toward commercial sex. The greatest risk factors were experiences of work out of town $(\mathrm{AOR}=2.46,95 \% \mathrm{CI}=1.02-5.91)$.

\section{Discussion}

Comparing with illicit drug use, high-risk sexual behaviors are more common among elderly men from rural areas in Chengdu. We conducted the investigation in Summer, and missed around 6\% [15.09\% (within the past 1 year) $\times 39.84 \%$ (other cities in Sichuan Province)] elderly men who migrated outside Chengdu. The adjusted prevalence of commercial heterosexual behavior was $11.22 \%$ $[(94 * 11.07 \%+6 * 13.55 \%) / 100 \times 100 \%]$, and was underestimated by $1.33 \%$ [(11.22\%-11.07\%)/(11.22\%)×100\%].

It is understandable that single respondents were more likely to be involved in commercial heterosexual behavior. Similar with other elderly men in the world [14], most of the respondents' sexual desire declined after the age of 50. The older, the less the respondents reported visiting FCSW, but visiting FCSW is not related to sexual desire change. This finding is in concord with the fact that visiting FCSW is not only to fulfill physical needs but emotional needs also [25, 41]. People often think that the conservative attitude could be a restriction against commercial heterosexual behavior [42]. In our survey, it is true among the mild objectors who are against this behavior. Surprisingly statistics found no difference in participating numbers of the commercial heterosexual behavior between the following two groups: accepting it as a natural human behavior verses strong objection. Since the 1980s, sexual attitudes in China have changed from procreation within a family context to being an individual's responsibility as long as there is no foreseen negative impact on the wellbeing of others or the larger society [42]. However, due to convention [42] and stigma [43], Chinese, especially elderly people, do not talk about sex [44], elderly men involving in commercial heterosexual behaviors may be too shy to admit it. It can only become more difficult to access the HIV education for them than in other age groups.

Worldwide, there is huge regional variation of highrisk sexual behaviors [45], mainly determined by structural factors, such as social and economic context [45, 46]. The greatest risk factors for commercial heterosexual behavior in this study were experiences of work out of town. Since the 1980s, rural-to-urban migration have been part of their lives for men from rural areas in China. In this study, more than half of the respondents had rural-to-urban migration experience. They were sexually active migrating alone [47, 48], easy to be involved in high-risk sexual behaviors [27, 31]. Their first visit to FCSW mostly happened during their migration. Visiting FCSW was cheap and easy to get access. No one used condoms consistently, mainly because of lack of skills and knowledge. Condom in China has been used mainly for contraception, meanwhile the main contraception method among married couples were intrauterine device (IUD) for women [49]. When they were young, respondents did not take major responsibility for contraception, neither did they have too much chances to learn how to use condom, someone even never used condom in their lifetime. Moreover, carrying condom in brothels is taken as an evidence for visiting FCSW in China where sex work is illegal [49], which hold elderly men from initiating condom use when visiting FCSW.

In this study, receiving HRHE through mass media,which cover all groups of population [39] and has been part of the systematic HIV prevention [5], helped elderly men avoid visiting FCSW. Health facilities have played an important role in improving elderly men's HIV knowledge, but been far from success. In terms of "90-90-90 targets", even though it is not impossible to achieve the goals of $90 \%$ of HIV diagnosed population receiving sustained ART, as well as $90 \%$ of those receiving ART be viral suppressed by 2020 , it is very hard to achieve $90 \%$ of diagnosis rate. Not only because free HIV testing is a voluntary action in China [5], but also one of five elderly men have not even heard the term of HIV/AIDS, let alone utilizing the free test. Current HIV prevention strategies in County A succeed in reducing blood transmission route, and most elderly men are aware of blood transmission route and none use illicit drugs through injections. However, HIV related knowledge level among elderly men is very low (31.41\%). There are misunderstandings about transmission routes and stigma toward PLHIV which probably hold them back from utilizing the free test [43]. When they were detected as HIV positive, it is highly possible that they had been infected for a long time. During their undetected HIV status, they would infect their sexual partners unintentionally. FCSW infected by elderly men will also infect other age group men $[25,31-33,50]$. That is why elderly men have been listed as key groups in HIV prevention in 2017 [19].

\section{Limitations}

The current study should be noted including a crosssectional study design and self-report behavior 
Table 4 Association between lifetime commercial heterosexual behavior and related factors among HIV negative elderly men who have heard about HIV/AIDS, bivariate and multivariate analyses $(n=624)$

\begin{tabular}{|c|c|c|c|}
\hline & Higher value (\%) & UAOR $(95 \% \mathrm{Cl})$ & AOR $(95 \% \mathrm{Cl})$ \\
\hline Age: $\geq 60$ vs. 50-59 & 69.39 & $0.54(0.34-0.86)$ & $0.41(0.19-0.91)$ \\
\hline Education level & & & - \\
\hline Primary school vs. primary school drop outs & 21.79 & $0.64(0.34-1.21)$ & \\
\hline Junior high school vs. primary school drop outs & 29.17 & $1.33(0.8-2.19)$ & \\
\hline Senior high school and above vs. primary school drop outs & 8.97 & $0.26(0.06-1.12)$ & \\
\hline \multicolumn{4}{|l|}{ Marital Status } \\
\hline Married vs. never married & 84.29 & $0.19(0.07-0.52)$ & $0.04(0-0.52)$ \\
\hline Married but separated vs. never married & 5.13 & $0.41(0.12-1.43)$ & $0.11(0.01-2)$ \\
\hline Divorced/widowed but have one partner vs. never married & 1.76 & $0.42(0.09-2.1)$ & $0.22(0.01-7.1)$ \\
\hline Divorced/widowed vs. never married & 7.53 & $0.34(0.1-1.12)$ & $0.39(0.02-6.34)$ \\
\hline Experiences of work out of town & 65.22 & $2.14(1.27-3.6)$ & $2.46(1.02-5.91)$ \\
\hline Daily entertainment- exercises & 17.95 & $0.37(0.17-0.78)$ & - \\
\hline Daily entertainment-watching TV & 56.09 & $0.6(0.38-0.93)$ & - \\
\hline Daily entertainment-visiting tea house with friends & 67.79 & $1.76(1.06-2.91)$ & - \\
\hline Monthly expense for entertainment & & & - \\
\hline 500-999 vs. < 500YUAN & 15.87 & $3.78(2.25-6.36)$ & \\
\hline $1000-1499$ vs. $<500 Y \cup A N$ & 4.97 & $1.29(0.44-3.78)$ & \\
\hline $1500-1999$ vs. $<500 Y U A N$ & 1.60 & $0.82(0.11-6.38)$ & \\
\hline 2000 and above vs. $<500$ YUAN & 1.60 & $2.13(0.45-9.97)$ & \\
\hline Receiving HRHE from TV, internet, and radio & 70.49 & $0.33(0.18-0.61)$ & $0.37(0.16-0.85)$ \\
\hline Self-identified vulnerable to get HIV infected. & 7.69 & $5.53(2.93-10.45)$ & - \\
\hline \multicolumn{4}{|l|}{ Attitudes toward commercial sex } \\
\hline Undecided vs. Accepting it as a natural human behavior & 26.92 & $0.02(0.01-0.04)$ & $0.02(0.01-0.09)$ \\
\hline Objection vs. Accepting it as a natural human behavior & 40.06 & $0.02(0.01-0.04)$ & $0.04(0.01-0.1)$ \\
\hline Strongly objection vs. Accepting it as a natural human behavior & 11.22 & $0(0-)$ & $0(0-)$ \\
\hline Attitudes towards HIV infected family and friends if happens & & & - \\
\hline Be fearful and stay far away vs. care for him/her more than before & 29.65 & $1.85(0.67-5.06)$ & \\
\hline Express sympathy but stay far away vs. care for him/her more than before & 23.88 & $3.28(1.21-8.85)$ & \\
\hline Express sympathy and keep in touch vs. care for him/her more than before & 22.60 & $1.66(0.58-4.75)$ & \\
\hline Treat him/her as usual vs. care for him/her more than before & 12.66 & $1.07(0.31-3.67)$ & \\
\hline
\end{tabular}

Note: -refers not in the model

information. Face-to-face interviews may heighten socially desirable responses such as conservative attitudes toward high-risk behaviors, and low report of high-risk sexual behaviors. In order to confront the problems, our interviewers were well trained, interviews were conducted in separate room, and local slangs were used.

Migration experience is a risk factor for high-risk sexual behavior. At the time of investigation, we missed around 6\% elderly men who migrated outside Chengdu. Fortunately, the prevalence of commercial heterosexual behavior in this study was only underestimated by $1.33 \%$.

Due to limited sample size for bisexual respondents, we cannot draw the conclusions that bisexual elderly men were more likely to be involved in high-risk sexual behaviors than heterosexual ones, but the fact that both two self-identified bisexual respondents were involved in commercial heterosexual behaviors gave a clue for further study.

\section{Conclusions}

Comparing with illicit drug use, high-risk sexual behaviors are more common among elderly men from rural areas in Chengdu. HIV related knowledge level among elderly men is very low (31.41\%). Receiving HRHE from mass media and undecided and objection attitude toward commercial sex prevent elderly from being involving in commercial heterosexual behavior. 
According to the results, health intervention strategies for elderly men could be the following: Health facilities continue to conduct systematic interventions, paying more attention to 50-59 years old group. Sex and condom use need to be talked in public. Working with mass media, health facilities give elderly men health education not only focusing on transmission route of HIV/AIDS, but also on knowledge and skills of condom use.

\section{Abbreviations}

ART: Antiretroviral therapy; HIV/AIDS: Human immunodeficiency virus/ Acquired Immune Deficiency Syndrome; UNAIDS: The Joint United Nations Programme on HIV/AIDS; PLHIV: People living with HIV; FCSW: Female commercial sex workers; MSM: Men who have sex with men; CRIMS: the web-based National HIV/AIDS Comprehensive Response Information Management System; CDC: Center for disease prevention and control; ELISA: Enzyme-linked immunosorbent assay; KAP: Knowledge-attitudepractice; HRHE: HIV-related health education; UNGASS: United Nations General Assembly Special Session on HIV/AIDS; AOR: Adjusted odds ratio; IUD: Intrauterine device

\section{Acknowledgments}

We would like to acknowledge the contributions of six township health centers, Pengzhou District CDC, and Chengdu CDC, and Guotao Luo, Yunrui Bai, Xuesong Wang, Fengsheng Leng, Yiji Wan, Run Zhong Wang in the data collection. We also thank Shuya Bi and Catherine Schricker for editorial assistance.

\section{Authors' contributions}

YY analyzed the data and was a major contributor in writing the manuscript. $\mathrm{HD}$ and $\mathrm{HH}$ helped to wrote and double checked the manuscript. SF, YL helped to analyze the data. XW, NL, J. Xi, J. Xu, J. Xiao, RL, and WX organized and conducted the investigation. All authors read and approved the final manuscript.

\section{Funding}

This study was supported by National Natural Science Foundation of China (Grant \#81803300) and humanities and social science projects of the Ministry of Education of China (Grant \#18YJA840018).

\section{Availability of data and materials}

The datasets analyzed during the current study are available from the corresponding author on reasonable request.

\section{Declarations}

\section{Ethics approval and consent to participate}

The institutional review board (IRB) from affiliated hospital of Chengdu University of Traditional Chinese Medicine approved the protocol (reference number: 2019KL-008). All methods were performed in accordance with the relevant guidelines and regulations including a statement. A written informed consent was completed before the face-to-face structured interviews, and respondents agreed that their information can be published anonymously if needed.

\section{Consent for publication}

NA.

\section{Competing interests}

The authors declare that they have no competing interests.

\section{Author details}

${ }^{1}$ Department of Social Medicine and Health Administration, School of Administration, Chengdu University of Traditional Chinese Medicine, 1166 Liutai Avenue, Wenjiang District, Chengdu 611137, China. ${ }^{2}$ Department of Urology, Chengdu Second Peoples' Hospital, 10 Qingyunnan Road, Chengdu 610017, China. ${ }^{3}$ School of Public Administration, Southwestern University of Finance and Economics, 555 Liutai Avenue, Wenjiang District, Chengdu, China. ${ }^{4}$ Department of HIV/AIDS prevention, Chengdu Center for Disease
Control and Prevention, No.4, Longxiang Road, Wuhou District, Chengdu 610000, China. ${ }^{5}$ Department of Epidemiology and Health Statistics, School of Public Health, Chengdu University of Traditional Chinese Medicine, 1166 Liutai Avenue, Wenjiang District, Chengdu 611137, China. ${ }^{6}$ Department of HIV/AIDS prevention, Pengzhou Center for Disease Control and Prevention, 331 Longta Road, Pengzhou District, Chengdu 610000, China.

Received: 8 March 2021 Accepted: 28 October 2021

Published online: 15 November 2021

\section{References}

1. Wang H, Wolock TM, Carter A, Nguyen G, Kyu HH, Gakidou E, et al. Estimates of global, regional, and national incidence, prevalence, and mortality of HIV, 1980-2015: the global burden of disease study 2015. Lancet Hiv. 2016;3(8):E361-87. https://doi.org/10.1016/S2352-3018(16)30087-X.

2. Lancet T. The global HIV/AIDS epidemic-progress and challenges. Lancet. 2017;390(10092):333. https://doi.org/10.1016/S0140-6736(17)31920-7.

3. Piot P, Abdool Karim SS, Hecht R, Legido-Quigley H, Buse K, Stover J, et al. Defeating AIDS-advancing global health. Lancet. 2015;386(9989):171-218. https://doi.org/10.1016/50140-6736(15)60658-4.

4. UNAIDS. 90-90-90-an ambitious treatment target to help end the AIDS epidemic. 2014; Available from: http://www.unaids.org/en/resources/ documents/2014/90-90-90.

5. Zhang, L., et al., Comprehensive HIV/AIDS Programs in Sichuan. HIV/AIDS in China 2019: p. 629-651, DOl: https://doi.org/10.1007/978-981-13-8518-6_33.

6. Degenhardt L, Mathers BM, Wirtz AL, Wolfe D, Kamarulzaman A, Carrieri MP, et al. What has been achieved in HIV prevention, treatment and care for people who inject drugs, 2010-2012? A review of the six highest burden countries. Int J Drug Policy. 2014;25(1):53-60. https://doi.org/10.1016/j. drugpo.2013.08.004.

7. Nguyen N, Holodniy M. HIV infection in the elderly. Compr Ther. 2008;3(3): $453-72$.

8. Negin J, Cumming RG. HIV infection in older adults in sub-Saharan Africa: extrapolating prevalence from existing data. Bull World Health Organ. 2010; 88(11):847-53. https://doi.org/10.2471/BLT.10.076349.

9. Qiao Y-C, et al. Epidemiological analyses of regional and age differences of HIV/AIDS prevalence in China, 2004-2016. Int J Infect Dis. 2019;81:215-20. https://doi.org/10.1016/j.jiji.2019.02.016.

10. Liu H, Lin X, Xu Y, Chen S, Shi J, Morisky D. Emerging HIV epidemic among older adults in Nanning, China. AIDS Patient Care STDS. 2012;26(10):565-7. https://doi.org/10.1089/apc.2012.0227.

11. High KP, et al. HIV and aging: state of knowledge and areas of critical need for research. A report to the NIH Office of AIDS Research by the HIV and Aging Working Group. Jaids I Acquired Immune Deficiency Syndromes. 2012;60(Suppl 1):S1-18.

12. Smit M, Brinkman K, Geerlings S, Smit C, Thyagarajan K, Sighem Av, et al. Future challenges for clinical care of an ageing population infected with HIV: a modelling study. Lancet Infect Dis. 2015;15(7):810-8. https://doi.org/1 0.1016/S1473-3099(15)00056-0.

13. Leng SX, Margolick JB. Aging, sex, inflammation, frailty, and CMV and HIV infections. Cell Immunol. 2020;348:104024. https://doi.org/10.1016/j. cellimm.2019.104024.

14. Diokno AC, Brown MB, Herzog AR. Sexual function in the elderly. Arch Intern Med. 1990;150(1):197-200. https://doi.org/10.1001/archinte.1990.003 90130161026

15. Zhang L, Chow EPF, Jing J, Zhuang X, Li X, He M, et al. HIV prevalence in China: integration of surveillance data and a systematic review. Lancet Infect Dis. 2013;13(11):955-63. https://doi.org/10.1016/S1473-3099(13)70245-7.

16. Kang S-C, Hwang S-J, Wong W-W. Characteristics of human immunodeficiency virus infections among the elderly in Taiwan: a nationwide study. J Chin Med Assoc. 2011;74(5):215-9. https://doi.org/10.1 016/j.jcma.2011.03.006.

17. Jia ZW, et al. Tracking the Evolution of HIV/AIDS in China from 1989-2009 to Inform Future Prevention and Control Efforts. PLoS One. 2011;6(10). https://doi.org/10.1371/journal.pone.0025671.

18. Cui Y, Shi CX, Wu Z. Epidemiology of HIV/AIDS in China: recent trends. Global Health J. 2017;1(1):26-32. https://doi.org/10.1016/\$2414-6447(19)3 0057-0.

19. Council, O.o.C.S, China's 13th Five-year Action plan for AIDS prevention and control. 2017. 
20. Tucker JD, Henderson GE, Wang TF, Huang YY, Parish W, Pan SM, et al. Surplus men, sex work, and the spread of HIV in China. Aids. 2005;19(6):53947. https://doi.org/10.1097/01.aids.0000163929.84154.87.

21. Thakor HG, Kosambiya JK, Desai VK. Knowledge and practices related to sexually transmitted infections and HIV among sex workers in an urban area of Gujarat, India. J Indian Med Assoc. 2010;108(1):12-7.

22. Siddiqui AUR, et al. Condom use during commercial sex among clients of Hijra sex workers in Karachi, Pakistan (cross-sectional study). BMJ Open. 2011;1(2):1(2). https://doi.org/10.1136/bmjopen-2011-000154.

23. Reilly KH, Wang J, Zhu Z, Li S, Yang T, Ding G, et al. HIV and associated risk factors among male clients of female sex workers in a Chinese border region. Sex Transm Dis. 2012;39(10):750-5. https://doi.org/10.1097/OLQ. 0b013e31825f7af7.

24. Zhang C, Li X, Su S, Zhang L, Zhou Y, Shen Z, et al. Prevalence of HIV, syphilis, and HCV infection and associated risk factors among male clients of low-paying female sex workers in a rural county of Guangxi, China: a crosssectional study. Sex Transm Infect. 2014;90(3):230-6. https://doi.org/10.1136/ sextrans-2013-051275.

25. Yang Y, Yang C, Latkin CA, Luan R, Nelson KE. Condom Use During Commercial Sex Among Male Clients of Female Sex Workers in Sichuan China: A Social Cognitive Theory Analysis. AIDS Behav. 2016;20(10):1-9. https://doi.org/10.1007/s10461-015-1239-z.

26. Lau JTF, Wang M, Wong HN, Tsui HY, Jia M, Cheng F, et al. Prevalence of bisexual behaviors among men who have sex with men (MSM) in China and associations between condom use in MSM and heterosexual behaviors. Sex Transm Dis. 2008;35(4):406-13. https://doi.org/10.1097/OLQ.0b013e3181 $64467 f$.

27. Song $Y$, et al. HIV-testing behavior among young migrant men who have sex with men (MSM) in Beijing, China. Aids Care. 2011;23(2):179-86.

28. Liao M, Kang D, Jiang B, Tao X, Qian Y, Wang T, et al. Bisexual behavior and infection with HIV and syphilis among men who have sex with men along the east coast of China. AIDS Patient Care STDS. 2011;25(11):683-91. https:// doi.org/10.1089/apc.2010.0371.

29. Huang $L$, et al. Sociodemographic and sexual behavior characteristics of an online MSM sample in Guangdong, China. AIDS Care. 2014;26(5):648-52. https://doi.org/10.1007/978-3-476-00516-8_64.

30. Chow EPF, Lau JTF, Zhuang X, Zhang X, Wang Y, Zhang L. HIV prevalence trends, risky behaviours, and governmental and community responses to the epidemic among men who have sex with men in China. Biomed Res Int. 2014;2014:1-19. https://doi.org/10.1155/2014/607261.

31. Wang B, Li X, Stanton B, Fang X, Lin D, Mao R. HIV-related risk behaviors and history of sexually transmitted diseases among male migrants who patronize commercial sex in China. Sex Transm Dis. 2007;34(1):1-8. https:// doi.org/10.1097/01.olq.0000222668.95038.03

32. Fosados R, Caballero-Hoyos R, Torres-López T, Valente TW. Condom use and migration in a sample of Mexican migrants: potential for HIV/STI transmission. Salud Publica Mex. 2006;48(1):57-61. https://doi.org/10.1590/ s0036-36342006000100009.

33. Saggurti N, et al. Male migration and risky sexual behavior in rural India: Is the place of origin critical for HIV prevention programs? BMC Public Health. 2011;11(SUPPL. 6):S6.

34. Zhang TQ, et al. Awareness of HIV/AIDS and its routes of transmission as well as access to health knowledge among rural residents in Western China: a cross-sectional study. BMC Public Health. 2019;19(1):19(1). https://doi.org/1 0.1186/s12889-019-7992-6.

35. Stall, R. and J. Catania, AIDS Risk Behaviors Among Late Middle-aged and Elderly Americans 1994. 154(1): p. 57-63, DOI: https://doi.org/10.1001/a rchinte.154.1.57.

36. Tuddenham SA, Page KR, Chaulk P, Lobe EB, Ghanem KG. Patients fifty years and older attending two sexually transmitted disease clinics in Baltimore, Maryland. Int J STD AIDS. 2017;28(4):330-44. https://doi.org/10.1177/09564 62416646687.

37. Fsya B, et al. Epidemiological and spatiotemporal analyses of HIV/AIDS prevalence among older adults in Sichuan, China between 2008 and 2019: a population-based study - ScienceDirect. Int J Infect Dis. 2021.

38. Zhenhua D, Shuangfeng F, Rong L, Xueqing W, Yaying S, Zhijun L, et al. Consistently high HIV prevalence among men who have sex with men in Chengdu city from 2009 to 2014. Int J STD AIDS. 2015;27(12):1057-62. https://doi.org/10.1177/0956462415606251.

39. Ministry of Industry and Information Technology of the People's Republic of China. Telephone users by province in June 2019. 2019. Available from: https://www.miit.gov.cn/gxsj/tjfx/txy/art/2020/art_b255416f73ec483fb754a c621f19217f.html.

40. Organization, G.W.H. Monitoring the Declaration of Commitment on HIV / AIDS. In: Guidelines on construction of core indicators. 2008 reporting. Geneva Switzerland: UNAIDS; 2007.

41. Pan S, Parish WL, Huang Y. Clients of female sex workers: a populationbased survey of China. J Infect Dis. 2011;204(SUPPL. 5):S1211-7. https://doi. org/10.1093/infdis/jir537.

42. Zhang K, Beck EJ. Changing sexual attitudes and behaviour in China: implications for the spread of HIV and other sexually transmitted diseases. Aids Care. 1999:11(5):581-9. https://doi.org/10.1080/09540129947730.

43. Genberg BL, Hlavka Z, Konda KA, Maman S, Chariyalertsak S, Chingono A, et al. A comparison of HIV/AIDS-related stigma in four countries: negative attitudes and perceived acts of discrimination towards people living with HIV/AIDS. Soc Sci Med. 2009;68(12):2279-87. https://doi.org/10.1016/j. socscimed.2009.04.005

44. Yang Y, Luan RS, Liu P, Wu CL, Zhou Y, Chen W. Casual sex and concurrent sexual partnerships among young people from an Yi community with a high prevalence of HIV in China. Asian J Androl. 2012;14(5):758-65. https:// doi.org/10.1038/aja.2012.25.

45. Wellings K, Collumbien M, Slaymaker E, Singh S, Hodges Z, Patel D, et al. Sexual behaviour in context: a global perspective. Lancet. 2007;368(9548): 1706-28. https://doi.org/10.1016/S0140-6736(06)69479-8.

46. Shannon K, Strathdee SA, Goldenberg SM, Duff P, Mwangi P, Rusakova M, et al. Global epidemiology of HIV among female sex workers: influence of structural determinants. Lancet. 2015;385(9962):55-71. https://doi.org/10.101 6/S0140-6736(14)60931-4.

47. Wu XG, Treiman DJ. The household registration system and social stratification in China: 1955-1996. Demography. 2004;41(2):363-84. https:// doi.org/10.1353/dem.2004.0010.

48. Wong DFK, Li CY, Song HX. Rural migrant workers in urban China: living a marginalised life. Int J Soc Welf. 2007;16(1):32-40. https://doi.org/10.1111/ j.1468-2397.2007.00475.x.

49. Zou H, Xue H, Wang X, Lu D. Condom use in China: prevalence, policies, issues and barriers. Sex Health. 2012;9(1):27-33. https://doi.org/10.1071/SH11021.

50. Yang H, Li X, Stanton B, Liu H, Liu H, Wang N, et al. Heterosexual transmission of HIV in China: a systematic review of behavioral studies in the past two decades. Sex Transm Dis. 2005;32(5):270-80. https://doi.org/1 0.1097/01.olq.0000162360.11910.5a.

\section{Publisher's Note}

Springer Nature remains neutral with regard to jurisdictional claims in published maps and institutional affiliations.

Ready to submit your research? Choose BMC and benefit from:

- fast, convenient online submission

- thorough peer review by experienced researchers in your field

- rapid publication on acceptance

- support for research data, including large and complex data types

- gold Open Access which fosters wider collaboration and increased citations

- maximum visibility for your research: over $100 \mathrm{M}$ website views per year

At BMC, research is always in progress.

Learn more biomedcentral.com/submissions 